\title{
The Interaction of Noetic and Psychosomatic Operations in a Thomist Hylomorphic Anthropology
}

\section{DANIEL DE HAAN}

TWCF Fellow, Faculty of Divinity \& Department of Psychology, University of Cambridge daniel.d.dehaan@gmail.com ORCID: 0000-0001-8656-3610

\begin{abstract}
This article, the second of a two-part essay, outlines a solution to certain tensions in Thomist philosophical anthropology concerning the interaction of the human person's immaterial intellectual or noetic operations with the psychosomatic sensory operations that are constituted from the formal organization of the nervous system. Continuing with where the first part left off, I argue that Thomists should not be tempted by strong emergentist accounts of mental operations that act directly on the brain, but should maintain, with Aquinas, that noetic operations directly interact with psychosomatic operations. I develop a Thomist account of noetic-psychosomatic interactions that expands upon the first part's rapprochement between the new mechanist philosophy of neuroscience and psychology and hylomorphic animalism. I argue that noetic-psychosomatic interactions are best understood as analogous to the way diverse higher and lower order psychosomatic powers interact by actualizing, coordinating, and directing the operations of other psychosomatic powers. I draw on James Ross's arguments for the immateriality of intellectual operations as realizing definite pure functions in order to elucidate the way noetic operations uniquely actualize, coordinate, and direct the psychosomatic operations they interact with. I conclude with a conjectural sketch of how this presentation of Thomist philosophical anthropology understands the noetic and psychosomatic deficits brought about by damage to the nervous system.
\end{abstract}

Scientia $e t$ Fides $6(2) / 2018,55-83$ 
Keywords: hylomorphism; new mechanist philosophy; neuroscience; psychology; philosophical anthropology; aristotelianism; intellectual and psychosomatic operations; Thomas Aquinas; thomism; James Ross; emergentism.

\section{Abbreviations for the works of St. Thomas Aquinas \\ DV Quaestiones disputatae de veritate \\ In DA Sentencia libri De anima \\ In I Cor Super primam epistolam ad Corinthios lectura \\ QDdA Quaestiones disputatae de anima \\ QDSC Quaestio disputata de spiritualibus creaturis \\ SCG Summa contra gentiles \\ ST Summa theologiae}

This article, the second of a two-part essay on Thomist philosophical anthropology and neuroscience, takes as its point of departure the account of hylomorphic animalism (HMA) and new mechanistic philosophy (NMP) of neuroscience and psychology presented in the previous article. In the present article, I articulate a speculative framework for understanding how immaterial intellectual operations can interact with other psychological operations that are embodied in the nervous system. Said otherwise, this article aims to develop a contemporary version of Aquinas's claim that the human intellect-an entirely immaterial power-is able to engage with the phantasms produced by the embodied powers of the internal senses.

Let us commence with a cursory summation of the three sections of the previous article (De Haan 2017b). In the first section, I presented an account of $H M A$ that I distinguished from the more contentious claims of a Thomist hylomorphic personalism (THP) which countenances immaterial noetic or intellectual powers in addition to the embodied psychological powers of animals. For $H M A$, all the psychological powers of an animal are embodied, and many are hylomorphically embodied in the nervous system. Just as the substance of the animal is constituted from the formal organization of its matter, so also the psychosomatic powers and operations of the animal are constituted from zones of organized material components, like the nervous system. Animals are fundamental entities for HMA, and it is the substance 
of the animal that grounds its psychological, neurophysiological, and other biological, chemical, and physical attributes. The animal's psychological attributes are constituted from the formal organization of its sub-psychological neurophysiological components, which are in turn constituted from the formal organization of various biochemical components, and so forth. ${ }^{1}$

In the second section, I showed how the general ontological framework of HMA can be filled out by the NMP's approach to neuroscience and psychology. NMP distinguishes four elements found in the hierarchical levels of mechanisms investigated by neuroscience: the organization of component entities and their component activities which function together to bring about the phenomenon of the mechanism taken as a whole. In the third section, I established that Aristotelian HMA is fundamentally incompatible with strong emergentism (SE), including versions of $S E$ that purport to be Aristotelian. I then introduced a criticism leveled against $S E$ by some proponents of $N M P$ and showed why this criticism does not present any problems to $H M A .{ }^{2}$ In brief, unlike $S E, H M A$ maintains that all psychological attributes of animals are embodied insofar as they are constituted from the organization of biological components of the animal.

This brings us to the more contentious claims of Thomist hylomorphic personalism, especially those concerning the interaction of immaterial intellectual powers with the other psychosomatic powers of the rational animal. How does THP fit within the less controversial picture provided by $H M A$ and $N M P$ ? In this article, I present a speculative answer to these important questions beginning with the way Thomist hylomorphic personalism amplifies Thomist hylomorphic animalism.

1 In the first article, I introduced the well-known distinction between personal and sub-personal level attributes. In this article, I shall reserve this distinction for human persons and will employ a similar distinction between psychological and sub-psychological (or animal and sub-animal) level attributes in my treatment of topics common to humans and other animals.

2 Elsewhere I have argued that HMA can accommodate the insights of NMP and that HMA's ontology of animal psychology can find in NMP the prospects of a complementary philosophy of biology, neuroscience, psychology. I take such claims for granted in this essay. See De Haan 2017a. 


\section{Thomist Hylomorphic Personalism}

Because human persons are rational animals, Thomists approach both humans and other animals as unified wholes that can be understood by first describing their activities in the world, then analyzing these integrated activities into distinct objects and operations, which in turn illuminate the distinct powers possessed by humans and other animals, which help us to understand the substance and nature that distinguishes humans from other animals. In a word: from an experienced, understood, conceptualized, and verified multi-form unity, we begin the arduous task of differentiating the objects, operations, and powers grounded by a substance's nature. This analysis is ultimately ordered towards a unified and integrated description and explanation of the whole (See ST I.77.1-8; In DA II, lt. 5-6). This phenomenological cum philosophical analysis of the given polymorphic unity of conscious human experiences refracts into the myriad formal objects intentionalized by different psychological operations of apprehension: visibles by seeing, audibles by hearing, tangibles by touching, affordances by enactive perceptual registrations, imagables by imagining, intelligibles by intellectual abstraction, insight, conceptualization, and rational verification.

Thomas Aquinas, like most medieval Aristotelians, maintained that intellectual operations and the intentionalized intelligibles they apprehend completely transcend the conditions of materiality. Consequently, neither intellectual operations nor the intellectual powers that enable these noetic operations are embodied in biological organs like the nervous system. Aquinas writes,

Some powers of the soul, namely the intellect and will, are in the soul insofar as it exceeds the total capacity of the body; hence, powers of this sort are not said to be in any part of the body. Other powers, however, are common to the soul and the body, hence each of these powers ... is only in that part of the body which is adapted (proportionata) to the operation of such a power. ST I.76.8ad4 ${ }^{3}$

3 See also QDSC, 2 ad5. All translations from the works of Thomas Aquinas are my own unless stated otherwise. Because my aims in this essay are not exegetical, but philosophical, my translations focus more on communicating the meaning of the text to a contemporary audience, rather than providing a literal translation of technical Scholastic nomenclature. 
Nevertheless, the intellectual powers and their operations, like all psychological powers, are grounded in the human soul which is the substantial form of the human body. The human soul, however, is an intellectual soul that can subsist without the body, because it is an immaterial subsistent principle. Aquinas explains:

The human soul's mode of existence can be known from its operation. For insofar as the human soul has an operation that transcends materiality, its existence transcends the body and does not depend on the body.... Therefore, if the human soul insofar as it is united as form to the body also has an existence that transcends the body, and does not depend on the body, it is manifest that the soul itself is established on the boundary between corporeal and separate substances. QDdA 1 (Leon., 10: 337-341).

Because intellectual operations transcend the conditions of matter and cannot be reduced to any psychosomatic properties, the very being and subsistence of the human person and its animating substantial form cannot be reduced to any embodied or material principles. Aquinas contends that the immateriality of the intellectual soul does not undermine his view that the human person is a hylomorphically constituted animal, because, like the sensory soul of other animals, the intellectual soul can animate and organize the organic body as its substantial form. ${ }^{4}$ The intellectual soul:

4 "One must claim that the intellect, which is the principle of intellectual operation, is the form of the human body. For that by which something primarily operates (primo operatur) is the form of that to which the operation is attributed. For instance, that by which the body is primarily healed is health, and that by which the soul primarily knows is knowledge (scientia); hence, health is a form belonging to the body, and knowledge is a form belonging to the soul. The reason for this is that nothing acts except insofar as it is actually such-and-such, and so that by which it is actually such-and-such is that by which it acts. But it is obvious that the soul is that by which the body is primarily alive. And since life is made manifest by different operations within the different grades of living things, the soul is that by which we perform each of these vital acts. For instance, the soul is that by which we primarily assimilate nourishment (nutrimur), have sensory cognition (sentimus), and move from place to place (movemur secundum locum); and, similarly, the soul is that by which we primarily have intellective understanding (intelligimus). Therefore, this principle by which we primarily have intellective understanding-regardless of whether it is called the intellect or the intellective soul-is the form of the body." ST I.76.1 (Freddoso, mod. trans.). See ST I.75.2; QDdA 1. 
is separated with respect to its intellectual power, because the intellectual power is not a power that belongs to any corporeal organ, as the power of vision is the act of the eye. For intellectual understanding is an act that cannot be performed by a corporeal organ, in the way that vision is exercised. But it is in matter insofar as the soul itself, to which the intellectual power belongs, is the form of the body and the terminus of human generation. ST I.76.1ad1.

Finally, as with other animals, the human person is neither the soul nor the body, nor any one or more of their psychological powers. Aquinas maintains that "the soul is not the whole human, and I am not my soul." (In I Cor. 15, lt. 2 n. 924, Marietti, 411). The individual human person and their human nature is identified with the entire rational animal, the complete subsistent composite of rational soul and organic matter. ${ }^{5}$

Thomas Aquinas's subtle doctrine and contentious arguments for the immateriality of the intellectual operations, powers, and soul have been treated extensively throughout the centuries and in the contemporary literature, so I will not rehearse them here. ${ }^{6}$ What I aim to explore is how the human person's immaterial noetic operations-which transcend the conditions of matter-are able to interact with psychosomatic operations that are embodied as the formal organization of the material organs of the rational animal.

First, let us rehearse why Aquinas's hylomorphic personalism, like his hylomorphic animalism, is not a form of strong emergentism. In the previous article, I noted that $S E$ is a kind of dualism, and both emergent substance dualism and emergent property dualism maintain that the irreducible novel emergent mind, self, agent, or person, and any emergent mental properties, fundamentally depend upon and emerge from the complex organized physical substance and its properties. Mental entities depend on the physical entities that produce them. The challenge for $S E$ as a philosophy of mind is to provide a convincing story about how physical causes produce

$5 \quad$ See ST I.29.1ad5; 75.4. ST I.76.6.ad3; QDdA 1; QDSC 2, ad 2; Bazán 1997; Spencer 2014; De Haan and Dahm Forthcoming).

6 See Lonergan 1992, 538-44; Oderberg 2007; Feser 2013; Madden 2013, 265-274; Ross 2008, 1992; Haldane 2016; Klima and Hall 2011; Braine 1992, 2014. 
mental properties, how the novel properties of the mind can (efficiently) cause other mental effects and physical effects, and why these mental causes neither overdetermine nor are in competition with physical causes of these physical effects. Neo-Aristotelian HMA and THP not only reject the mental-physical dichotomy and its associated Crypto-Cartesian ontology, but also provide a completely different framework for understanding how psychosomatic and noetic attributes, like powers and their operations, are grounded in a substance constituted by the organization of matter by an animating substantial form.

For THP, the human person is a rational animal because it belongs to the nature of its substance to ground both immaterial noetic powers as well as essentially psychosomatic powers and to enable their integrated operations, which includes the wide range of activities that comprise human agency. When a human person acts or is acted upon these activities enlist a panoply of noetic and psychosomatic powers-and the organized hierarchical complex of neural, biochemical, and physical subsystems that constitute psychosomatic powers-whose coordinated and integrated operations enable the human person to perform the activities in question. For $S E$, however, mental or psychological properties exert some kind of mental force or efficient causality on independently existing and functioning physical properties, like the nervous system, bodily limbs, and so forth. Hence, for $T H P$, the entire concert of noetic and psychosomatic activities involved in running to catch a bus constitute the observable psychological behavior of the human, whereas for $S E$, psychological attributes are restricted to the non-observable mind, whose mental causes-like intentions or desiresefficiently cause extrinsic bits of matter in the brain which in turn produce the observable non-psychological bodily behavior of running after the bus (Zahavi 2011; Bennett and Hacker, 2003).

Second, Aquinas not only claims the operations of the human person's psychosomatic powers for sensation, perception, phantasia, and emotion interact with intellectual and volitional operations, he also contends that this interaction is natural and continuous. Indeed, "it is impossible for our intellect ... to understand anything actually, except by turning to the phantasms." 
(ST I.84.7) ${ }^{7}$ The intelligibles intentionalized by the intellect are abstracted from phantasms, which are comprised of a constellation of perceptual recognition sortals, memories, a treasury of linguistic schemata, and a host of other phenomena we can consciously experience (e.g., imagery, emotions, pains). ${ }^{8}$ Intellectual understanding and conceptualization are the offspring of the intellectual desire to understand the world the human encounters as a rational animal. But intellectual understanding and conceptualization about the world can be knowledge only if understood conceptualizations have been rationally verified in a judgment that truly grasps such-and-such is the case. ${ }^{9}$ And this requires intellectual reflection on the phantasms as well as vigilant observations and continuous active exploration of the world. In short, our intellect's natural and constant orientation is directed towards the reality we experience as rational animals. Aquinas writes, "in order for the intellect to be actually engaged in intellective understanding-not only for attaining knowledge de novo, but also for making use of already acquired knowledge-what is required are acts of the imagination and of the other powers.” (ST I.84.7. Freddoso mod. trans.). Human affectivity, motivations, emotions, intentions, deliberations, choices, and voluntary intentional actions are no different in this respect, but that is a more complex story to be told another day. ${ }^{10}$

See ST I-II.9.1; DV 24.5 (Lonergan 1992; Lonergan 1997; Ross 2008; Braine 1992, 2014).

8 See Ross 2008, 97. Wonder, the desire to know, and abstraction are preconditions for intellectual operations of rational enquiry, understanding, formulation, rational reflection, and judgmental understanding-the operations Aquinas attributes to a noetic power called the potential intellect (intellectus possibilis). Wonder-along with any acquired virtues of a disciplined intelligent enquirer that enhance wonder-disposes one's capacity for intellectual abstraction insofar as it aims one's intellectual discrimination and attention towards what is relevant over what is irrelevant. Metaphysically speaking, abstraction is a distinct operation for intellectual intentionalization that Aquinas attributes to a noetic power called the active intellect (intellectus agens). For Aquinas, the abstractive operation of the active intellect produces actually immaterial intentionalized intelligible content that is derived from an intelligent engagement with the potentially intelligible content of phantasms. See Aquinas, In DA III.4-5, lt. 7-10; ST I.54.4; 79.1-5; 84-89; Lonergan 1997, ch. 4.

9 See ST I.16.2; 17.2-3; 84.7-8; Lonergan 1988; Lonergan 1992; Ross 2008.

10 See Bennett and Hacker 2003; Hacker 2008; Nachev and Hacker 2014; Brock 1998; Wojtyła 1979; De Haan 2011; De Haan 2014. 
Additionally, it is worth noting that both linguistic apprehension and expression are part and parcel of the complex coordinated operations of the internal sensorium that Aquinas calls phantasia. Indeed, the intellect's natural proclivity to be constantly oriented to the phantasms has been rightly interpreted by Bernard Lonergan, Etienne Gilson, James Ross, David Braine, Alasdair MacIntyre, and many others to reflect Aquinas's deep appreciation of how crucial language is, not just for expressing human knowledge, but more fundamentally for facilitating intellectual enquiry, understanding, conceptualization, rational reflection, intelligent judgments, practical reasoning, and thinking within the medium of words. ${ }^{11}$ Intellectual understanding is constantly being deployed in tandem with the exercise of our linguistic capacities along with the concert of psychosomatic powers that comprise them.

In sum, a Thomist philosophical anthropology rejects emergent dualism and its Crypto-Cartesian framework for mental causation and is committed instead to Neo-Aristotelian hylomorphism, even in the case of human persons. But Thomist hylomorphic personalism also maintains that the noetic powers and operations grounded in the soul of rational animals are completely disembodied. And yet, these noetic operations of intellect and will constantly interact with the neurophysiologically embodied psychological operations of sensing, perceptually registering, imagining, remembering, and having somatic affections, passions, and emotions. How are these irreducibly immaterial noetic operations capable of interacting with these essentially psychosomatic operations?

\section{Noetic and Psychosomatic Interactions in a Thomist Hylomorphic Personalism}

I propose to address this question in two stages. The interaction among distinct psychosomatic operations provides an initial paradigm that I then extend to include the intellectual operations of the intellect. So, the for-

11 See Braine 1992; Braine 2014; Lonergan 1997; Gilson 1988; MacIntyre 1999; Ross 2008; De Haan 2010. 
mer paradigm helps us to work out how noetic operations interact with psychosomatic operations. In order to make clear what exactly intellectual operations contribute to psychosomatic operations like seeing, hearing, touching, perceptually registering, being motivated, having emotions, executing purposive behavior, imagining, and remembering, I draw on James Ross's arguments for the immateriality of intellectual operations. Ross's arguments are based on the impossibility of any wholly physical system realizing definite mathematical and logical forms or pure functions-like conjunction, addition, and modus ponens-that are naturally and ubiquitously employed in human intellectual operations.

\subsection{Psychosomatic Interactions in a Thomist Hylomorphic Animalism}

Humans (and other animals) deploy a range of personal level (or animal level) psychosomatic abilities, call these psychological level attributes. These psychosomatic abilities can be distinguished into lower-level psychosomatic operations like seeing, hearing, and touching, and higher-level psychosomatic operations like enactive perceptual and estimative registration, memory, motivation, emotion, and a range of executive functions. These higher-level and lower-level psychosomatic operations are all animal level attributes, which admit of a surfeit of sub-animal level attributes, such as the complex hierarchy of multilevel mechanisms identified by NMP. Lower-level and higher-level psychosomatic operations interact with each other in a variety of complex ways. Sometimes the lower-level psychosomatic operations are actualized by environmental stimuli which thereby drive the coordinated manifestations of higher-level psychosomatic operations. In other cases, the animal's powers for enactive perception, motivation, and executive registrations enable the animal to exert effective control over the coordinated manifestation of its higher-level and lower-level psychosomatic powers, such as the animal's capacities for enactive sensory perception and motivation that guide locomotion.

What does this technical jargon mean? In the first case, a dog sees a colored moving object, perceptually registers it as a squirrel that affords 
pursuit, which thereby motivates the dog to chase the squirrel. In the second instance, the dog is conveying a freshly slain rabbit to its pups when it notices a squirrel darting across its path, but because the dog is sufficiently determined towards its present course, the motivation to chase the squirrel is inhibited and the dog continues on its way.

Each of these psychosomatic operations enlists a distinct, though interactive, cascade of coordinated manifestations of powers constituted from organized hierarchies of neurophysiological and other biological levels of mechanisms. And just as neural assemblies in the visual cortex interact with neural assemblies in the medial temporal lobe, parietal lobe, frontal lobe, and so forth, so also the animal's conscious seeing directly interacts with and shapes or is shaped by its conscious enactive perceptions and executive registrations to do something. For instance, an animal's psychosomatic powers for executive registrations enable the animal to recognize and engage with salient affordances in its environment or to pursue objects that will satisfy some biopsychosocial imperative. Executive registrations also enable the animal to control its attention and inhibit distracting affordances-evoked by environmental or endogenous stimuli, e.g., fleeing squirrels or the pangs of hunger-that might motivate it to switch tasks while it is pursuing a determinate goal. Animal agency of this kind requires that the operations of an animal's psychosomatic powers are able to inhibit other psychosomatic powers, while also coordinating and organizing the conscious operations of other powers, and ordering or directing them to the achievement of the biopsychosocial imperatives that presently occupy the animal's attention. In order for a dog to return home to its pups, it must be able to harness and direct its enactive capacities for seeing, hearing, smelling, tasting, touching, perceiving, executive registering, and bodily movements to the task at hand, without being distracted by the kaleidoscope of other salient affordances it passes by along the way. ${ }^{12}$ This quotidian example

12 Behavioral and cognitive psychology are replete with experiments on classical and operant conditioning and their connection to forms of stimulus versus cognitive or executive control, all of which demonstrate how executive functions like inhibitory control are crucial for enabling the animal to override stimulus-driven responses. This data is impressive 
provides a clear illustration of how distinct psychosomatic powers are able to interact with other psychosomatic powers by directing and controlling the coordinated manifestations of some psychosomatic powers while inhibiting the manifestation of others. The directed operations function as material potentialities or instruments to be actualized and formally ordered by the directing operations. Aquinas drew a similar conclusion in his treatment of the unity of human action.

Now just as, in the case of a genus of natural things, a whole is composed of matter and form, in the way that a man is composed of soul and body, and yet is one natural being even though it has many parts, so too, in the case of human acts, the act of a lower power is related as matter to the act of a higher power because the lower power acts in virtue of the higher power's actualizing it; for the act of the first agent is related as a form to the act of its instrument. Hence, it is clear that the act of commanding and the commanded act are one human act, just as a whole is one, but many in its parts. ST I-II.17.4 (Freddoso, mod. trans.).

While I do not have space to develop and defend the point here, this account of interactions among the psychosomatic powers of an animal requires that we distinguish between mechanistic organization and psychological organization. Mechanistic organization explains the way psychosomatic powers, their operations, and diverse forms of psychological organization among these powers and operations are constituted from and enabled by the organized sub-psychological level interactions among neural and other biological components. Psychological organization explains the psychological level interactions between the animal's psychosomatic powers and objects in the animal's environment; it concerns the way the manifestations or

and important, however, my presentation of executive registrations and functions, as well as my understanding of the relevant data differs in important respects from the way this data is interpreted in the models of executive function discussed in cognitive psychology. My claim here is that in many cases, inhibitory control is not simply an activity attributed to various sub-animal or sub-psychological level information filters carried out by the "cognitive information processing" capacities of the nervous system. Rather, this kind of neural inhibition (or "cognitive" inhibition) must be distinguished from a genuinely psychosomatic form of inhibition, which is a form of psychological organization proper to the psychological level attributes of the animal. 
operations of psychosomatic powers are actualized, coordinated, and directed by their reciprocal disposition partners, that is, by other psychosomatic powers and/or the powers of objects in the environment (Jaworski 2016, 2017; Marmodoro 2017). Psychological organization pertains to the animal's conscious intentionality that comprises its psychological behavior, such as its conscious attention to and pursuit of a biopsychosocial imperative that inhibits the manifestation of some psychosomatic powers (which, via mechanistic organization, inhibits the neurophysiological mechanisms that underlie and constitute these psychosomatic powers). Psychological organization is distinct from the mechanistic organization characterized by NMP because the powers and operations of vision and audition are not to be understood as the organized mechanistic components of the psychosomatic powers and operations of estimative registration, memory, emotion, or executive function (or vice-versa). Additionally, psychological organization pertains to the distinctively psychological level of the interaction among psychosomatic powers and so the kind of coordinating and directing organization that comprises the conscious intentionality of an animal. In short, psychological organization is the form of organization proper to conscious intentionality, which is absent from the kind of (causal) activities that comprise the mechanistically organized components of sub-psychological attributes of the animal.

Finally, this form of psychological organization is a characteristically hylomorphic form of organization; to understand it along the lines of strong emergentism would be a mistake. This is because the phenomenon of an animal with conscious intentionality is not a $S E$ mental property extrinsic from the physical base that generates it; it is a psychological level attribute of an animal that is the phenomenon constituted from the mechanistic organization of sub-psychological neural and other biological components of the animal's psychosomatic powers. As with all of the other phenomena characterized by the $N M P$, the phenomenon of conscious intentionality is what the mechanistic organization of components taken as a whole constitute. And, just as no amino acid can do what a protein constituted from the organization of amino acids can do, and no individual component of 
a neuron can generate what constitutes the action potential of a neuron, so also none of the sub-psychological activities of the organized components of the psychosomatic powers of the animal exhibit conscious intentionality. Consider corvids. A corvid that experiences other birds stealing the food it caches in their presence, learns to re-cache its food once the other birds are absent (Shaw and Clayton 2012; Legg and Clayton 2014). The psychological phenomena of vision, estimative registration, memory, learning, and executive control that comprise the flexible psychological behavior of corvids are explained by the psychosomatic powers of the bird, not merely by its sub-psychological components. So, even though the different psychosomatic powers and operations that comprise the conscious intentionality of an animal are all constituted from organized sub-psychological components, the distinctive way in which these conscious psychosomatic powers interact qua psychological level attributes comprises a form of psychological organization that is not only absent from all of the mechanistic interactions among the sub-psychological components of these distinct psychosomatic powers, but also fails to meet the NMP's criteria for mechanistic organization.

Clearly, this is but a pencil sketch that requires more detailed argumentation to justify this account of interactions among psychosomatic powers and to distinguish different forms of biopsychosocial conditioning, learning, and cognitive flexibility exhibited in animal behavior. But I hope what I have said will be sufficient to help elucidate the more controversial contention of Thomist hylomorphic personalism, namely, that a similar kind of interaction can obtain between these embodied psychosomatic operations and disembodied immaterial noetic operations.

\subsection{Definite Pure Functions Realized by Noetic Operations}

For HMA, conscious psychosomatic operations, and the powers that ground them, are irreducible animal level attributes that are nevertheless essentially hylomorphically constituted from the organization of multilevel nervous and other biological systems, that is, sub-animal level attributes. These psychosomatic operations can interact directly with other psychosomatic 
operations by inhibiting their actualization or by actualizing, coordinating, and directing their operations. $H M A$, combined with $N M P$, provides an alternative paradigm to standard Crypto-Cartesian accounts of mental causation and the interaction of distinct forms of conscious psychological operations. This alternative Neo-Aristotelian paradigm supports arguments that contend it is unnecessary, problematic, and even conceptually confused to hold that the only way for mental causation to work, requires that psychological or mental operations be extrinsic efficient causes that directly cause physical effects in the brain.

What does Thomist hylomorphic personalism add to hylomorphic animalism? THP extends HMA's paradigm for the interaction between psychosomatic operations to include the way noetic operations can interact with psychosomatic operations. THP also rejects standard accounts of action and mental causation wherein the mind directly acts on the brain as an extrinsic mental force or rationalizing efficient cause (For similar critiques, see Hyman 2015; Vogler 2016; Teichmann 2015; Stoutland 2011). For THP, intellectual operations directly engage with psychosomatic operations, in part, by coordinating the manifestation of these powers. And the coordinated manifestation of these psychosomatic powers enlists the organized causal powers of the sub-psychological neurophysiological mechanisms that constitute these psychosomatic operations and powers. And like the paradigm case of psychosomatic operations, it is not mere efficient causality but formal and final causality that are critical for understanding the interaction between noetic operations and psychosomatic operations. What makes noetic operations and powers significantly different from psychosomatic ones, is that they are not embodied or constituted by the organization of any biofunctional parts of the rational animal, like the brain. So, unlike psychosomatic powers and operations, these noetic powers and operations transcend the conditions of matter and are thereby wholly grounded in the intellectual soul of the human person. What problems are generated by this account of disembodied noetic powers and operations interacting with embodied psychosomatic powers and operations? 
This is an important question, however, a better place to start, I think, is with the arguments made on behalf of this peculiarly Neo-Aristotelian doctrine that intellectual operations alone transcend the bodily organs that materially constitute the other psychological powers of human persons. Recall that Thomist philosophical anthropology commences with the polymorphic unity of the human person's conscious engagement with the world. The psychological activities of human persons integrate conscious operations such as sensation, perception, intellectual insight, conceptualization, rational judgments, emotion, and intentional action; this integration unifies different intentional objects into the polymorphic or multiform intentional objects of conscious awareness. Phenomenological and philosophical analysis reflectively isolate among our conscious experiences of objects the invariant patterns of conscious activity that are united under the headings "intellectual operations" or "noetic operations.” In short, we already know that intellectual operations can be integrated with sensory and perceptual operations because we begin with the polymorphic unity of conscious operations and only later reflectively distinguish within this unified manifold "perceptual operations" from "intellectual operations." This basic unity of conscious operations and intentional objects is one of many psychological facts that provide the point of departure for Thomist philosophical anthropology (Lonergan 1988; MacIntyre 2006). The difficulty is working out a coherent and cogent explanation of the ontological features of these intellectual operations and how they interact with psychosomatic operations.

Many Neo-Aristotelians, like Aquinas, argue that intellectual operations exhibit certain essential features that reveal they must be intrinsically separate from the ontological conditions of matter, and so are immaterial. There are two noteworthy principles at work in these arguments which are developed out of the hylomorphic framework of a Neo-Aristotelian ontology. First, there is something about the conditions of materiality that excludes or prevents certain properties from being embodied. Second, the features essential to noetic operations are among the properties excluded by materiality, which is why they completely transcend the conditions of matter, conditions that belong to every hylomorphic composite. Both tra- 
ditional and contemporary Neo-Aristotelian accounts of the immateriality of intellectual operations provide arguments that support both of these principles. My interest here is with the second principle.

In general, Neo-Aristotelian defenses of the second principle focus on why the form or content of these intellectual operations establish the intellect's transcendence or immateriality. Aquinas championed arguments that addressed both the universal content of noetic operations and the universal forms of operations manifested by the intellect, like its completely self-reflexive acts of understanding. More recently, James Ross has contributed a number of insightful arguments to the stock of Neo-Aristotelian defenses of the immateriality of intellectual operations. Ross's arguments focus more on the forms of intellectual thought than their content. I do not have space here to rehearse the details of Ross's ingenious argument or to defend it. A brief summary will be sufficient to show how the central insight of Ross's argument also sheds light on what intellectual operations alone can contribute to conscious experience by ordering and teleologically directing the form and content presented by psychosomatic operations (See Ross 1992; Ross 2008, ch. 6; Feser 2013).

First, Ross acknowledges that the range of animal abilities for cognition and appetition can be explained in some fashion by physical explanations; a claim that is compatible with my account of HMA and NMP. Second, human understanding, that is, "judgmental understanding capable of truth or falsity," (Ross 2008, 197, n. 5) is different in principle from these psychosomatic operations; it cannot be wholly explained by any kind of physical explanation, including the ontologically generous kinds of explanation provided by $H M A .{ }^{13}$ Third, Ross, like Aquinas, maintains that human understanding in this life always involves “a physical medium in-which.” (Ross 2008, 116). He notes, "it is only the understanding element that I am now trying to show cannot

13 In their insightful account of radical enactivist cognition, Daniel Hutto and Erik Myin introduce a similar distinction between the basic intentionality of nonhuman animals and the truth-content involving intentionality of rational animals. Aristotelians will find a lot to appreciate in the work of Hutto and Myin and it is worth considering what bearing Ross's arguments would have on their naturalistic account of radical enactivist cognition and what they call the "hard problem of content." See Hutto and Myin 2013, 2017. 
be wholly physical; understandings that involve sensation or feeling cannot be entirely nonphysical either, anymore than my going for a walk can be a mere willing." (Ross 2008, 197, n. 5). It is truth-carrying understanding or thinking that Ross contends requires intrinsic features that "no physical thing or process can have at all.” (Ross 2008, 116). What are these ontological immaterial remainders essential to truth-carrying understanding that cannot in principle be explained by wholly physical processes?

Developed and integral [human persons] have the native ability and constant proclivity ... to discern, recognize, and rely on intelligible, repeatable, structures of things, many of which are active and explanatory.... Such ability cannot be reductively physical... [because of such facts as] the underdetermination of the physical relatively to pure functions, [which] disclose that no entirely physical thing can do operations that realize pure functions determinately, yet, any integral human does that constantly. (Ross 2008, 115).

Ross's central claim is that human judgmental understanding realizes definite pure functions all of the time, and that no wholly physical process can realize definite pure functions. The prevalence of intellectual operations performing such definite pure functions should not be underestimated. Ross has in mind all intelligent realizations of any definite pure function from logic or mathematics, or, for instance, any of the pure functions that are touched upon in the late E.J. Lowe's Forms of Thought, such as reference, predication, identity, modality, conditionality, generality, negation, existence, and truth. These pure functions or forms of thought also include Bernard Lonergan's treatment of the normative exigencies of intelligence and rationality, as well as the late David Braine's account of the "general logic" that underlies and is incorporated into grammar (Lowe 2013; Lonergan 1992; Braine 2014, 36-47, 748-749). When I intellectually reason by employing a definite pure function, like modus ponens ("If $\mathrm{p}$ then q; $\mathrm{p}$; therefore q"), my intellectual operation realizes a definite form of valid reasoning. It cannot merely approximate the ideal form of modus ponens; my rational understanding must be a definite instance of that pure function that thereby excludes all incompossible pure functions (Ross 2008, 117-23). The reason why human 
judgmental understanding cannot be a mere simulation of or fail to be of a definite pure form is because if it did fail, then judgmental understanding would "fail to have the defining features of conjunction, disjunction, modus ponens, addition, and so on, upon which validity, consistency, and the like depend." (Ross 2008, 117).

In a word: our thinking, in a single case, can be of a definite abstract form (e.g., $\mathrm{N} \mathrm{x} \mathrm{N}=\mathrm{N}^{2}$ ), and not indeterminate among incompossible equally most particular forms.... No physical process can be that definite in its form in a single case. Adding physical instances even to infinity will not exclude incompossible equally most particular forms (cf. Saul Kripke's "plus/quus" examples). So, no physical process can exclude incompossible functions from being equally well (or badly satisfied...) Thus, no physical process can be the whole of such thinking. (Ross 2008, 116).

Ross anticipates the skeptical reactions of his analytic philosophy colleagues. He points out that many analytic philosophers not only attribute more bizarre features to propositions, but also, and more to the point, that his argument does not rest upon the peculiarity of certain ancient or medieval philosophical views, but on the "jewels of analytic philosophy: the underdetermination of hypotheses by data and the indeterminacy of the physical.” (Ross 2008, 116). ${ }^{14}$ And these widely held insights developed by $20^{\text {th }}$ century analytic philosophers entail that the limitations of physical objects or systems under the conditions of matter exclude the possibility for any wholly physical system to realize definite pure functions that determinately exclude all incompossible pure functions. ${ }^{15}$ But the realization

14 "No matter what a machine does or for how long, what it is doing remains formally indeterminate. That's supported by W.V.O. Quine's underdetermination claims, Nelson Goodman's "grue" reflections (1955, 63-86), and the "plus-quus" considerations of Kripke (1982, 9 and passim).” Ross 2008, 119. For Ross's references, see Goodman 1983; Kripke 1982.

15 Ross also anticipates the evasion that humans, like physical machines, merely simulate pure functions like contradiction and modus ponens; we might be able to define them, but we do not realize them. The problem with this dodge is that, "there is a pragmatic contradiction in denying that we can think in pure functions. To define such a function is to think in a form that is not indeterminate among incompossible forms. And to deny explicitly that we can do a specified operation, whether add, conjoin, [...] or define particular functions, like conjunction, is to do what is being denied. Such an epidemic of theoretical doubt as to what we can do, without any effect on one's own practical certainty, must involve a mistake." (Ross 2008, 121-22). 
of definite pure functions that do exclude all incompossible pure functions is characteristic of ordinary exercises of human intellectual understanding.

The details of Ross's argument and the defense of its premises is beyond the limits of this essay. I shall presume that Ross's argument is cogent. What does Ross's account of the immateriality of intellectual operations that realize definite pure functions tell us about the interaction of noetic operations with psychosomatic operations?

Even though they transcend the conditions of matter, the intellectual operations that really employ these definite pure functions are performed by human persons, and as Ross points out, they are regularly exercised in such a way that these intellectual operations organize and direct psychosomatic operations such that they are governed by these pure functions. Intellectual operations are constantly shaping or ordering our enactive capacities for perceptual registrations as well as any phenomenal presentations of phantasia. For example, human linguistic apprehension and expression involve psychosomatic operations, but these psychosomatic operations as such are not able to realize definite pure functions. However, when human persons ratiocinate intelligently they do deploy and realize definite pure functions in their intellectual thinking, and characteristically do so while thinking "in the medium of words," that is, by apprehending or expressing intelligent speech. And intelligent speech comprises the psychosomatic operations involved in linguistic production or expression that are governed, organized, and directed by intellectual operations that do realize definite pure functions like conjunction, modus ponens, modus tollens, and so forth. A complementary point is made by David Braine in his comprehensive study, Language and Human Understanding.

The brain is vital to us as bodily beings if our understanding is to find expression in speech and in coordination with perception, imagination, memory, emotion, and action. But the role of the brain is rather to facilitate our expression of understanding and thinking in the medium of words than to embody it. Our thinking is not embodied in language, but expressed using it; nor is it embodied in neural or imaginative sequences. The activities of understanding, thinking, and questioning, with their nonrepresentational character, combined with our 
freedom in the exercise of the capacity involved exhibited in the lack of definable limits to the flexibility in our use of words, show that these activities cannot be the work of any bodily organ. This does not make them the work of some other organ, but the activities of the person as such. (Braine 2014, 67).

What Ross's arguments bring to our attention is that, not only do human intellectual operations intentionalize a distinct kind of universal and transcendent content, but that they also understand that content according to definite forms of thought or pure functions via noetic operations that interact with psychosomatic operations by governing, ordering, and directing them in such a way that they derivatively exhibit the definite pure functions of our intellectual operations. In other words, noetic operations interact with psychosomatic operations via formal and final causality by rationally ordering and directing the manifestation of psychosomatic powers. If this were not true, then, according to Ross, I would not be able to intelligently think and express, via psychosomatic operations, sentences that are governed by definite pure functions, and you, the reader, would be incapable of intelligently apprehending them as manifesting the definite pure functions I intend them to exhibit. But I am intentionally articulating an argument that you, the reader, can understand as definitely exhibiting modus tollens and not modus ponens or any other incompossible pure functions. Hence, the antecedent is false. Human persons do perform integrated intellectual and psychosomatic operations whereby their immaterial intellectual operations interact with materially conditioned psychosomatic operations in at least one way, namely, by directing and organizing linguistic expressions according to the definite pure functions realized in intellectual operations. ${ }^{16}$

What does this account of noetic and psychosomatic operations from THP have to say in response to the challenge from NMP detailed in my previous article? Contrary to some proponents of $S E$, THP does not claim that there is direct empirical support from neuroscience for the existence

16 A similar account can be provided for the way practical reasoning and intentional actions are embodied in our psychological behaviors that are not also speech acts, see MacIntyre 2007, pp. 161-162 and chs. 14-15; MacIntyre 2006, ch. 5. 
of noetic operations or any downward mental causation that acts on the brain. Indeed, following Aquinas and Ross, the contention of THP is quite the opposite. First, the essential features of these intellectual operations that reveal their immateriality and transcendence from material conditions cannot be directly disclosed by the experimental investigations of neuroscience; rather, neuroscientists deploy these definite functions in the reasoning that orders their experimental investigations. Second, contrary to SE's account of downward mental causation, THP maintains that intellectual operations interact directly with psychosomatic operations, not with the nervous system. The noetic powers of the intellect and will engage the psychosomatic powers, not the sub-psychological powers of the nervous system that materially constitute these psychosomatic powers. Furthermore, the interactions between noetic and psychosomatic powers are principally via formal and final causality, not via any kind of extrinsic mental force directly causing effects in the brain. The intellect does not act on the brain and the brain does not act on the intellect; for THP there is no interfield mental-physical causation between the intellect and brain. Additionally, unlike the way psychosomatic powers and operations are constituted from something like the new mechanists' account of organized component entities and activities-like neural and other biological systems-psychosomatic powers and operations are not components that constitute noetic powers and operations. The organized manifestation of psychosomatic powers via the operations of our noetic powers is a form of rational or intellectual organization that is distinct both from the mechanistic organization that explains the way psychosomatic powers are constituted from sub-psychological neural systems, and from the non-rational psychological organization proper to the aforementioned interaction among psychosomatic powers. ${ }^{17}$ It therefore belongs to the very nature of these intellectual operations that

17 For an account of the way psychosomatic operations of humans and other animals that involve psychological organization are different from the noetic operations proper to human persons that involve rational organization, see Hutto 2008. Hutto's terminology, however, is quite different from my own, and his concerns are with psychological issues, not the more metaphysical ones I am addressing here. Indeed, Hutto's version of naturalism would reject THP's account of immaterial noetic powers. 
they do not admit of the kind of mechanistic explanations that NMP and $H M A$ provide for psychosomatic powers and operations. Consequently, $N M P$ 's challenge to $S E$, gets no purchase on THP, because THP maintains that noetic operations are strictly immaterial, do not emerge from the brain, do not have any kind of direct multilevel mechanistic explanation, and so cannot be directly supported, confirmed, or refuted by scientific evidence.

This conclusion, however, does not entail these explanations from NMP and HMA have no bearing upon the intellectual operations of THP. Just as Aquinas recognized that lesions in the brain could cause impairments to phantasia that adversely affected the human person's ability for intellectual understanding, so too our THP amplifications to NMP and HMA, can draw upon the latest in work in neuropsychology to make more precise explanations-or at least complementary explanations at a variety of different levels -for various psychological deficits. ${ }^{18}$ For instance, impediments to the causal processes of certain mechanistic components critical for higher-level psychosomatic operations, say, dorsolateral frontal lesions that adversely affect executive registrations, will thereby indirectly hinder the human person's ability to perform any intellectual operations that interact with, and so require the integrity of, such psychosomatic operations as executive registrations. Any unified activity of the human person requires the integrated operations of diverse reciprocal powers. Intellectual operations of practical reasoning and intentional action can only formally govern and direct executive registrations, memorative recollections, and the apprehension or articulation of intelligent speech if they are integrated with these psychosomatic operations. But there can be no such interaction between intellectual and psychosomatic operations if there are impediments to the exercise of these psychosomatic capacities. Impediments can arise at the psychological level of these psychosomatic capacities for perceptual registration, memory, and speech as well as at the sub-psychological level of the neural, genetic, and biochemical systems and subsystems that constitute and enable the proper functioning of these psychosomatic capacities.

18 See ST I.78.4; 84.7 89.5. See Craver 2007; Kendler, Zachar, and Craver 2011; Hughes 2011.

Scientia $t$ Fides $6(2) / 2018$ 
Consider the following very conjectural sketch for how the psychological and sub-psychological effects of Alzheimer's disease fit within THP. Neural cell death is hypothesized to result from beta-amyloid plaques and neurofibrillary tangles of the tau protein; the progression of these pathologies of the organized components of neurons leads to the degeneration of the neural systems constituted from the complex organization of networks of neurons. (Of course, this is extraordinarily simplified as I am leaving out a host of genetic and other intracellular and extracellular mechanisms and the entire scaffolding of multilevel mechanisms that bring us from neurons to neural systems.) The atrophy of the medial temporal lobe constituted from such deteriorating neural systems impedes the optimal functioning of the personal or psychological level psychosomatic powers and operations that are themselves constituted from and enabled by the organization of neural networks distributed throughout areas of the brain like the medial temporal lobe. Psychosomatic powers like memory-which are constituted from the organization of these atrophied sub-psychological neural systemswill be seriously hindered insofar as the manifestation of psychosomatic operations of recall and reminiscence depend upon enlisting the organized causal components of these sub-psychological neural systems. When the rational animal's psychosomatic capacities for recollection and reminiscence are inhibited by the atrophy of its sub-psychological neural systems, then not only will psychosomatic acts of recall be obstructed, so also will all forms of reminiscence that are otherwise governed and directed through interactions with intellectual operations. Intelligent narration that relies upon psychosomatic capacities for reminiscence will be thwarted whenever reminiscence is impeded. So, if reminiscence cannot be exercised-because it cannot enlist the capacities of the crucial neural systems that constitute memory due to neurodegeneration in the medial temporal lobe-then acts of reminiscence cannot be enlisted and guided by noetic operations, and intelligent narration becomes disabled.

In short, even though the deleterious effects of neurodegenerative disorders directly impact the psychosomatic powers and operations constituted from these deteriorating neural systems, they only indirectly impede 
intellectual powers and operations by inhibiting their capacity to formally govern, order, and direct psychosomatic operations. Any human activities that require the integrated confluence of noetic and psychosomatic operations-which for THP includes all intelligent activities of theoretical and practical reasoning and intentional action in this life-will be obstructed by damage to the sub-psychological neural systems that constitute and enable the psychosomatic powers of the rational animal.

\section{Conclusion}

This essay has, via two articles, brought together a variety of moving parts to amplify and clarify how a Thomist philosophical anthropology can engage and draw upon the riches of contemporary neuroscience, the new mechanist philosophy, hylomorphic animalism, and still maintain Aquinas's doctrine that the human intellect transcends bodily organs and yet exercises operations that are constantly interacting with the human person's essentially psychosomatic operations. In the course of these two articles, I have also endeavored to make clear how radically different the standard account of strong emergentism in philosophy of mind is from Neo-Aristotelian hylomorphic animalism and Thomist hylomorphic personalism. The emergentists approach ontological questions and even empirical work in neuroscience from the vantage point of a Crypto-Cartesian view of the mind; whereas hylomorphists approach ontological questions and neuroscientific and psychological research from an Aristotelian framework that begins with rational and other animals. Rational and other animals are fundamental entities that ground their noetic, psychosomatic, neurophysiological, and other biological, chemical, and physical attributes. The activities animals perform enlist the coordinated manifestations of their psychological and sub-psychological powers; impediments to lower-level powers inhibit the proper functioning of the higher-level powers constituted from the formal organization of these lower-level powers. Drawing upon the work of the new mechanist philosophy of neuroscience and psychology as well as James Ross's arguments for the immateriality of intellectual operations, I have shown 
that a Thomist philosophical anthropology can defend Aquinas's thesis that immaterial noetic operations constantly interact with psychosomatic operations-like whenever I communicate intelligent speech to you, the reader. If this study on Thomist philosophical anthropology is on the right track, then my intelligent speech is comprised of the immaterial noetic operations that realize definite pure functions that govern, shape, and direct the concert of psychosomatic operations that also comprise my speech acts. In short, intelligently thinking in the medium of words or expressing my thoughts to you, requires that I, a human person, can deploy together in a unified way my transcendent and immanent powers to produce a very concrete act of communication-like the communication of my thesis in this essay. How it is seen, heard, perceived, interpreted, doubted, refuted, rationally verified, amplified, or revised, is for you to determine. ${ }^{19}$

\section{References}

\section{Primary Sources}

Aquinas, Thomas. 2000. Quaestio disputata de spiritualibus creaturis. ed. J. Cos, Leonine, vol. 24/2. Rome.

Aquinas, Thomas. 1996. Quaestiones disputatae de anima. B.C. Bazan, Leonine, vol. 24/1. Rome.

Aquinas, Thomas. 1984. Sentencia libri De anima. ed. R.-A. Gauthier, Leonine, vol. 45/1. Rome.

Aquinas, Thomas. 1962. Summa theologiae. Rome: Editiones Paulinae.

Aquinas, Thomas. 1961. Liber de veritate catholicae Fidei contra errores infidelium seu

Summa contra Gentiles, t. 2-3. eds. P. Marc, C. Pera, P. Caramello. Rome: Marietti.

19 This essay developed out of a paper I presented at an interdisciplinary workshop entitled "Soul or Brain: What makes us human?" at the Nicolaus Copernicus University in Torun, Poland on 19-21 October 2016. I would like to thank the participants for their helpful comments and the organizers for their kindness and generosity. I must also thank Domenic D’Ettore, Antonio Ramos Díaz, Brandon Dahm, the anonymous reviewers, and Scientia et Fides editors for their feedback on earlier drafts of this essay. I am especially grateful to Antonio Ramos Díaz for sharing and discussing with me his excellent doctoral thesis on the arguments of Ross and Kripke. My research for this essay has been supported by the Templeton World Charity Foundation's Theology, Philosophy of Religion, and the Sciences project at the University of Cambridge. 
Aquinas, Thomas. 1953. Super Epistolas S. Pauli lectura, t. 1: Super primam Epistolam ad Corinthios lectura. ed. R. Cai. Marietti, Rome.

Aquinas, Thomas. Summa theologiae. trans. Alfred J. Freddoso, https://www3. nd.edu/ afreddos/summa-translation/TOC.htm

\section{Secondary Sources}

Bazán, Carlos. 1997. “The Human Soul: Form and Substance? Thomas Aquinas' Critique of Eclectic Aristotelianism.” Archives d'Histoire Doctrinale et Littéraire Du Moyen Âge 64: 95-126.

Bennett, M. R., and P. M. S. Hacker. 2003. Philosophical Foundations of Neuroscience. Malden MA: Blackwell Publishing.

Braine, David. 1992. The Human Person: Animal and Spirit. University of Notre Dame Press.

Braine, David. 2014. Language and Human Understanding: The Roots of Creativity in Speech and Thought. CUA Press.

Brock, Stephen. 1998. Action and Conduct: Thomas Aquinas and the Theory of Action. Edinburgh: T\&T Clarke.

Craver, Carl. 2007. Explaining the Brain: Mechanisms and the Mosaic Unity of Neuroscience. Oxford University Press.

De Haan, Daniel. 2017a. "Hylomorphism, New Mechanisms, and Explanations in Biology, Neuroscience, and Psychology" in Neo-Aristotelian Perspectives on Contemporary Science, eds. William M.R. Simpson, Robert C. Koons, Nicholas J. Teh. Routledge, 293-326.

De Haan, Daniel. 2017b. "Hylomorphic Animalism, Emergentism, and the Challenge of New Mechanisms in Neuroscience” Scientia et Fides 5 (2), 9-38.

De Haan, Daniel. 2014. "Moral Perception and the Function of the Vis Cogitativa in Thomas Aquinas's Doctrine of Antecedent and Consequent Passions." Documenti E Studi Sulla Tradizione Filosofica Medievale 25: 289-330.

De Haan, Daniel. 2011. “Thomistic Hylomorphism, Self-Determination, Neuroplasticity, and Grace: The Case of Addiction.” Proceedings of the American Catholic Philosophical Association 85: 99-120.

De Haan, Daniel. 2010. “Linguistic Apprehension as Incidental Sensation in Thomas Aquinas." Proceedings of the American Catholic Philosophical Association 84: 179-96.

De Haan, Daniel D., and Brandon I. Dahm. Forthcoming. "Thomas Aquinas on Separated Souls as Incomplete Human Persons.” 
Feser, Edward. 2013. “Kripke, Ross, and the Immaterial Aspects of Thought.” American Catholic Philosophical Quarterly 87: 1-32.

Gilson, Etienne. 1988. Linguistics and Philosophy an Essay on the Philosophical Constants of Language. University of Notre Dame Press.

Goodman, Nelson. 1983. Fact, Fiction, and Forecast. Harvard University Press.

Hacker, P. M. S. 2008. Human Nature: The Categorial Framework. Wiley-Blackwell.

Haldane, John. 2016. "Anscombe and Geach on Mind and Soul." American Catholic Philosophical Quarterly 90, 2: 369-394.

Hughes, Julian. 2011. Thinking Through Dementia. Oxford University Press.

Hutto, Daniel D. 2008. Folk Psychological Narratives: The Sociocultural Basis of Understanding Reasons. MIT Press.

Hutto, Daniel and Erik Myin. 2017. Evolving Enactivism: Basic Minds Meet Content. MIT Press.

Hutto, Daniel and Erik Myin. 2013. Radicalizing Enactivism: Basic Minds Without Content. MIT Press.

Hyman, John. 2015. Action, Knowledge, and Will. Oxford University Press.

Jaworski, William. 2017. "Psychology Without a Mental-Physical Dichotomy” In Neo-Aristotelian Perspectives on Contemporary Science, eds. William M.R. Simpson, Robert C. Koons, Nicholas J. Teh. 261-291. Routledge.

Jaworski, William. 2016. Structure and the Metaphysics of Mind: How Hylomorphism Solves the Mind-Body Problem. Oxford University Press.

Kendler, K. S., P. Zachar, and C. Craver. 2011. "What Kinds of Things Are Psychiatric Disorders?” Psychological Medicine 41 (6): 1143-1150.

Klima, Gyula, and Alexander W. Hall, eds. 2011. The Immateriality of the Human Mind, the Semantics of Analogy, and the Conceivability of God (Volume 1: Proceedings of the Society for Medieval Logic and Metaphysics). Cambridge Scholars Publishing.

Kripke, Saul A. 1982. Wittgenstein on Rules and Private Language: An Elementary Exposition. Harvard University Press.

Legg, Edward and Nicola Clayton. 2014. "Eurasian jays (Garrulus glandarius) conceal caches from onlookers.” Animal Cognition 17: 1223-1226.

Lonergan, Bernard. 1992. Insight: A Study of Human Understanding. University of Toronto Press.

Lonergan, Bernard. 1988. “Cognitional Structure.” In Collection, ed. Frederick E. Crowe and Robert M. Doran, 205-221. University of Toronto Press.

Lonergan, Bernard. 1997. Verbum: Word and Idea in Aquinas. ed. Frederick E. Crowe and Robert M. Doran. University of Toronto Press.

Lowe, E. J. 2013. Forms of Thought: A Study in Philosophical Logic. Cambridge University Press. 
MacIntyre, Alasdair. 2007. After Virtue, $3^{\text {rd }}$ ed. Notre Dame University Press.

MacIntyre, Alasdair. 2006. "What is a human body?" In The Tasks of Philosophy: Selected Essays, Volume 1. Cambridge University Press, 86-103.

MacIntyre, Alasdair. 1999. Dependent Rational Animals: Why Human Beings Need the Virtues. Open Court Publishing.

Madden, James D. 2013. Mind, Matter, and Nature: A Thomistic Proposal for the Philosophy of Mind. Catholic University of America Press.

Anna Marmodoro. 2017. “Aristotelian Powers at Work: Reciprocity without Symmetry in Causation.” In Causal Powers, ed. Jonathan Jacobs. Oxford University Press.

Nachev, Parashkev, and Peter Hacker. 2014. “The Neural Antecedents to Voluntary Action: A Conceptual Analysis.” Cognitive Neuroscience 5 (3-4): 193-208.

Oderberg, David S. 2007. Real Essentialism. Routledge.

Ross, James. 2008. Thought and World: The Hidden Necessities. Notre Dame University Press.

Ross, James. 1992. “Immaterial Aspects of Thought.” Journal of Philosophy 89 (3): $136-150$.

Shaw, Rachael and Nicola Clayton. 2012. "Eurasian jays, Garrulus glandarius, flexibly switch caching and pilfering tactics in response to social context." Animal Behavior 84: 1191-1200.

Spencer, Mark K. 2014. “The Personhood of the Separated Soul.” Nova et Vetera 12 (3): 863-912.

Stoutland, Frederick. 2011. “Introduction: Anscombe's Intention in Context.” In Essays on Anscombe's Intention. eds. Anton Ford, Jennifer Hornsby, and Frederick Stoutland. 1-32. Harvard University Press.

Teichmann, Roger. 2015. Wittgenstein on Thought and Will. Routledge.

Vogler, Candace. 2016. “Nothing Added: Intention §§19 and 20.” American Catholic Philosophical Quarterly 90 (2): 229-247.

Wojtyła, Karol. 1979. The Acting Person: A Contribution to Phenomenological Anthropology. Translated by Anna-Teresa Tymieniecka. Analecta Husserliana. Springer. Zahavi, Dan. 2011. “Empathy and Direct Social Perception: A Phenomenological Proposal.” Review of Philosophical Psychology 2: 541-558. 